\title{
Design of an ATV Gear Box
}

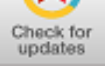

\section{Mohit Pillai, Naman Sharma, Vinit Bhandari, Ram Bansal}

\begin{abstract}
The main objective of the project was to design and fabricate a drive train for an intercollegiate competition called BAJA SAE. The motive to get into this project was to learn more about an All-Terrain Vehicle (ATV), studying about different parameter which would affect the drive train of the vehicle. All the possible options were considered while making the drive train. After discussions alternative options were taken neglected and the main option was chosen. It was decided that the transmission would be automatic, consist of a continuously variable transmission (CVT) couples with a two staged gearbox which is then couples with the half shaft. The whole system was tested thoroughly and it performed well.

Keywords: ATV, CVT, spur gear, compound gear train, gear box.
\end{abstract}

\section{INTRODUCTION}

In the ATV drive train consist of Engine which is coupled with a CVT, CVT is coupled with the compound gear train which is then connected to half shaft. The engine used in drive train is of Briggs and Stratton, the engine is of 305cc, producing $10 \mathrm{hp}$ and $19.2 \mathrm{NM}$ of torque at $2800 \mathrm{RPM}$. There are various transmission options like manual, semiautomatic, automatic. The problem with manual transmission is that you have to shift gears, that creates a problem for the drives as it would quite difficult for a driver to shift in an uneven, rough terrain. Same is the case with semi-automatic. While in automatic transmission there is no need of shifting as everything is automatic. In this case a CVT is selected for automatic transmission. CVT provides a maximum ratio of 3.9:1 in under drive condition and 0.75:1 in overdrive condition. The torque produced by the engine and CVT is not enough to run the vehicle, so the remaining torque is provided by gearbox which a compound gear train consist of two stage reduction.

\section{OBJECTIVES}

Design a system that would make the torque required to move the vehicle and to design a gearbox that would maintain the required centre distance between input shaft which is connected to secondary CVT and the output shaft which is connected to the half shaft. The system has to be cost effective, light weight and efficient.Vehicle) with an The gearbox is designed for an ATV (All-Terrain Vehicle) with an engine of following spec.

Revised Manuscript Received on March 16, 2020.

* Correspondence Author

Mohit Pillai*, Mechanical Engineering Department, Medi-Caps University, Indore, India, mohitpillai0298@gmail.com

Naman Sharma, Mechanical Engineering Department, Medi-Caps University, Indore, India,namansharma415@gmail.com

Vinit Bhandari, Mechanical Engineering Department, Medi-Caps University, Indore, India, vinitbhandai13@gmail.com

Ram Bansal, Mechanical Engineering Department, Medi-Caps University, Indore, India, ram.bansal@medicaps.ac.in

(c) The Authors. Published by Blue Eyes Intelligence Engineering and Sciences Publication (BEIESP). This is an open access article under the CC BY-NC-ND license (http://creativecommons.org/licenses/by-nc-nd/4.0/)

\section{Capacity: 305cc}

$>$ Maximum Torque: 19Nm @2800 rpm

> Maximum power: 10Hp @3800 rpm

\section{SIGNIFICANCE}

The findings of this study will redound for automotive society considering that power to weight ratio is consequential for an ATV. A final drive gear box provides a fixed reduction to overcome the lack of torque produced by the CVT in pair with the specified engine. This final drive gearbox is designed to produce maximum torque with high efficiency.

\section{DESIGN SPECIFICATION}

Table No. I - Gear Specification

\begin{tabular}{|l|l|l|l|l|}
\hline $\begin{array}{l}\text { Specificatio } \\
\mathrm{n}\end{array}$ & $\begin{array}{l}\text { Input } \\
\text { pinio } \\
\mathrm{n}\end{array}$ & $\begin{array}{l}\text { Intermediat } \\
\text { e pinion }\end{array}$ & $\begin{array}{l}\text { Intermediat } \\
\text { e gear }\end{array}$ & $\begin{array}{l}\text { Outpu } \\
\text { t gear }\end{array}$ \\
\hline $\begin{array}{l}\text { Number of } \\
\text { Teeth }\end{array}$ & 23 & 53 & 19 & 73 \\
\hline Module & 2 & 2 & 2.5 & 2.5 \\
\hline $\begin{array}{l}\text { Pressure } \\
\text { angle }\end{array}$ & $20^{\circ}$ & $20^{\circ}$ & $20^{\circ}$ & $20^{\circ}$ \\
\hline Face width & 12 & 12 & 15 & 15 \\
\hline $\begin{array}{l}\text { Pitch Circle } \\
\text { Diameter }\end{array}$ & 46 & 106 & 47.5 & 182.5 \\
\hline
\end{tabular}

a) Input shaft

Input pinion is integrated with the input shaft of the gearbox. Input shaft couples CVT to the gearbox through the splines.

b) Intermediate shaft

Intermediate shaft has intermediate pinion integrated on it and intermediate gear is mounted through a key way.

c) Output shaft

Output gear is mounted on to the output shaft through a key way. Half shafts are coupled with the help of splines.

d) Oil seals

Oil seals are used to prevent leakage of oil and it also oil and to also prevent dust particles from entering the gear box casing.

\section{e) Bearings}

Bearings used in gearbox are tapper roller bearing.

\section{DESIGN PROCEDURE}

Published By:

Blue Eyes Intelligence Engineering

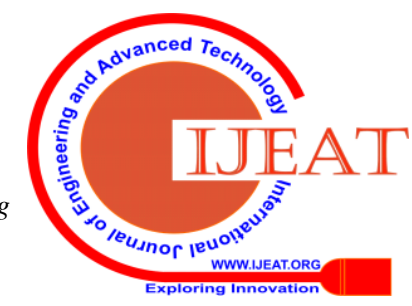




\section{Design of an ATV Gear Box}

a) Fixed parameters

Max engine RPM: 3800

Max vehicle speed: $60 \mathrm{kmph}$

Max engine torque: $19.2 \mathrm{Nm}$

Tyre diameter: 23 inches

Max gradient: $37^{\circ}$

CVT efficiency: $85 \%$

Spur gear efficiency: 94\%

Co-efficient of rolling resistance: 0.023

Gross weight: 220kg

b) Procedure

i. First the overall torque required for the vehicle to move was calculated, which gave us the total torque required.

ii. Engine torque is predefined and the ratio of the CVT is predefined, by dividing the overall torque to the engine torque and CVT's under drive ratio. This would give the final reduction of the gear box.

iii. Except for the torque required constrain there is another constrain, that the vehicle should reach top speed of $60 \mathrm{kmph}$.

iv. The max RPM of the engine was divided with the overdrive ratio of the CVT and the RPM of the wheels at $60 \mathrm{KMPH}$. This would give the reduction required to achieve $60 \mathrm{kmph}$.

v. The reduction in torque required condition and the max speed condition aren't the same. So, this gave us a range to work with.

vi. No. of teeth in each gear were taken as prime numbers so as to avoid tooth hunting, keep the overall gear ration between the torque required and max speed condition and to maintain the centre to centre distance between the input shaft and the output shaft of the gears.

vii. Half shaft is used to connect the gearbox to the wheel assembly. It is used to transmit torque at an angle. It has a constant velocity joint. In this case it is rzeppa. It is couples to the output shaft of the gearbox with the help of splines. The material used to make the half shaft is EN24.

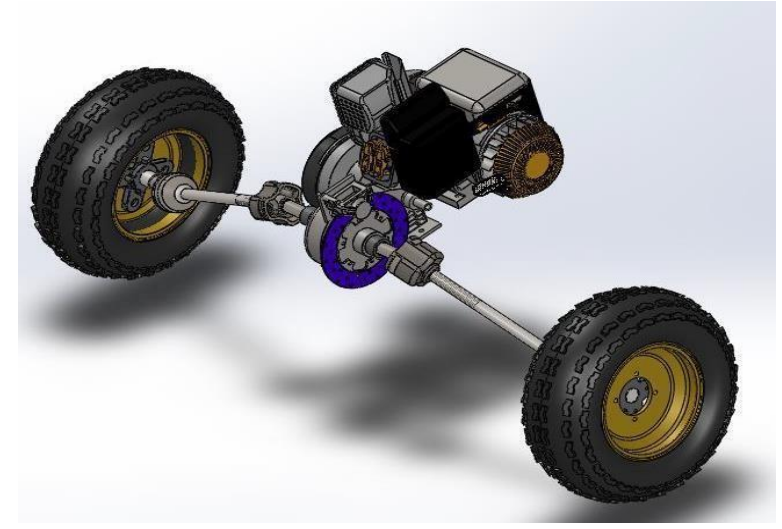

Figure Number 1- Engine Gearbox assembly

\section{CALCULATIONS}

Max torque required

Total resistance = rolling

+ aerodynamic drag + gradient resistance

Rolling resistance $=C r m g \cos \theta[6]$

Here, $\mathrm{C}_{\mathrm{r}}$ is coefficient of rolling resistance

$\mathrm{m}$ is mass of the vehicle and driver

Published By:

Blue Eyes Intelligence Engineering \& Sciences Publication

$\mathrm{g}$ is acceleration due to gravity

$\theta$ is gradient angle

Aerodynamic drag $=0.5 \rho A C d v^{2}[6]$

Here, $\rho$ is density of air

$A$ is front area of the vehicle

$\mathrm{C}_{\mathrm{d}}$ is aerodynamic drag coefficient

Gradient resistance $=m g \sin \theta[6]$

Here, $m$ is mass of vehicle with driver

$\mathrm{g}$ is acceleration due to gravity

$\theta$ is gradient angle

Torque required to move a vehicle $=$ (total resistance $\times$ radius of tyre $) / \eta[6]$

Here, $\eta$ is transmission efficiency

Gearbox reduction $=$ torque required $/($ engine torque $\times \max$ CVT ration in under drive condition)

Top speed condition

$\mathrm{RPM}$ of tyre at $60 \mathrm{kmph}=60 \times \omega / 2 \pi$

Here, $\omega$ is angular velocity

Gearbox reduction $=($ max engine $\mathrm{RPM} \times \mathrm{CVT}$ ratio in over drive condition)/RPM of tyre at $60 \mathrm{kmph}$.

The above two conditions gave us a range between 8.31 and 9.02. The overall reduction decided was 8.87 , as the no of teeth were taken as prime numbers to avoid tooth hunting.

Gear calculations

The module of the gears were decided.

Then the no. of were decided to maintain the gear ratio and avoid tooth hunting.

Then pitch circle diameter was calculated $\mathrm{d}=\mathrm{m} \times \mathrm{t}$.

Here, $d$ is pitch circle diameter, $m$ is module and $t$ is no of teeth.

The pressure angle was selected as $20^{\circ}$.

The addendum of gear is equal to its module.

Reddendum is equal to 1.25 times module.

Clearance is 0.25 times module.

Working depth is 2 times module.

Force calculation

Tangential Force, $F_{t}=$ $2 \times$ transmitted torque/d

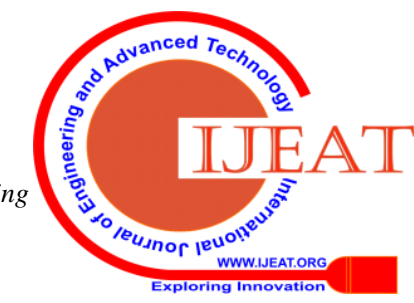


Here, d id pitch circle diameter[4]

Radial force, $\mathrm{F}_{\mathrm{r}}=F t / \tan \emptyset$

Here, $\varphi$ id pressure angle[4]

Normal Force, $\mathrm{F}_{\mathrm{n}}=\mathrm{Ft} / \cos \emptyset[4]$

Bending stress $=(F t \times d \times K a \times K m \times K s \times K y \times J) / b$ Here, $\mathrm{K}_{\mathrm{a}}$ is application factor, $\mathrm{K}_{\mathrm{m}}$ is load distribution factor, $\mathrm{K}_{\mathrm{s}}$ is size factor, $\mathrm{K}_{\mathrm{v}}$ is dynamic load factor, $\mathrm{J}$ is geometry factor, $\mathrm{b}$ is face width.[4]

Contact stress $=Z e \times \sqrt{(}(F t \times K a \times K m \times K y \times C f) /(b \times$ $d \times I))[4]$

Here, $\mathrm{C}_{\mathrm{f}}$ is surface condition factor, $\mathrm{Z}_{\mathrm{e}}$ is elastic coefficient, I is surface strength geometry factor.[4]

Wear stress $=b \times Q \times d \times K$ factor

Here, $\mathrm{Q}$ is ratio factor. [4]

\section{SOFTWARE USED}

Creo, the shorthand name for Creo Parametric, (formerly known as Pro Engineer) is a powerful and intuitive 3D CAD software . It is one of the leading 3D software used by organizations in multiple industries ranging from aerospace, automobile to consumer products.

Creo offers many workbenches that can be loosely termed as modules. A few of the important workbenches and their brief functionality description is given below:

Part Design: This Creo module makes it possible to design precise 3D mechanical parts with an intuitive and flexible user interface, from sketching in an assembly context to iterative detailed design.

Generative Shape Design: allows you to quickly model both simple and complex shapes using wireframe and surface features. It provides a large set of tools for creating and editing shape designs.

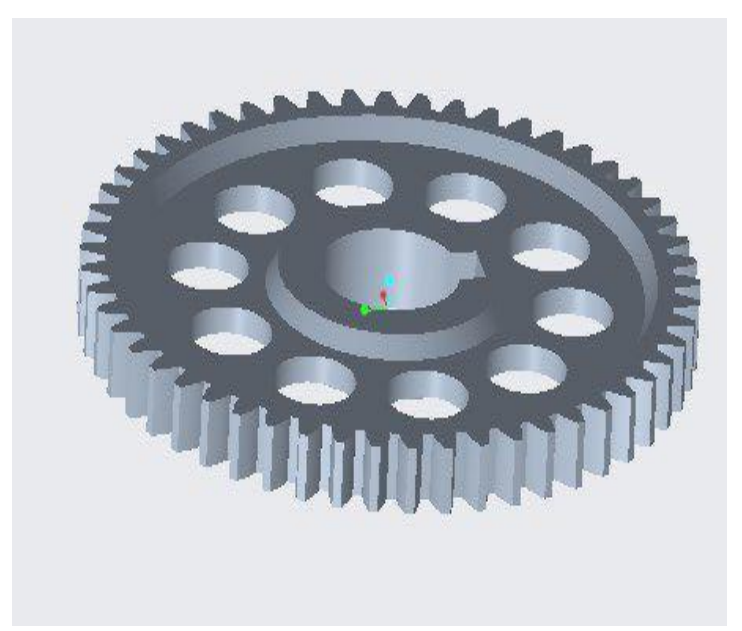

Figure Number 2- Model of pinion

Figure Number 3- Model of output gear

\section{ANSYS}

The ANSYS Mechanical software suite is trusted by organizations around the world to rapidly solve complex structural and thermal problems with ease. Structural

Published By:

Blue Eyes Intelligence Engineering \& Sciences Publication mechanics solutions from ANSYS provide the ability to simulate every structural aspect of a product, including nonlinear static analysis that provides stresses \& deformations, modal analysis that determines vibration characteristics, through to advanced transient nonlinear phenomena involving dynamic effects \& complex material behavior[14].

Using ANSYS Mechanical software solutions, you can import geometries of complex assemblies, optimally mesh them, and apply realistic boundary conditions. Following these pre-processing steps, you can perform analyses to assess the strength, vibration, motion and thermal response characteristics of the system. A variety of graphical tools allow you to easily visualize the

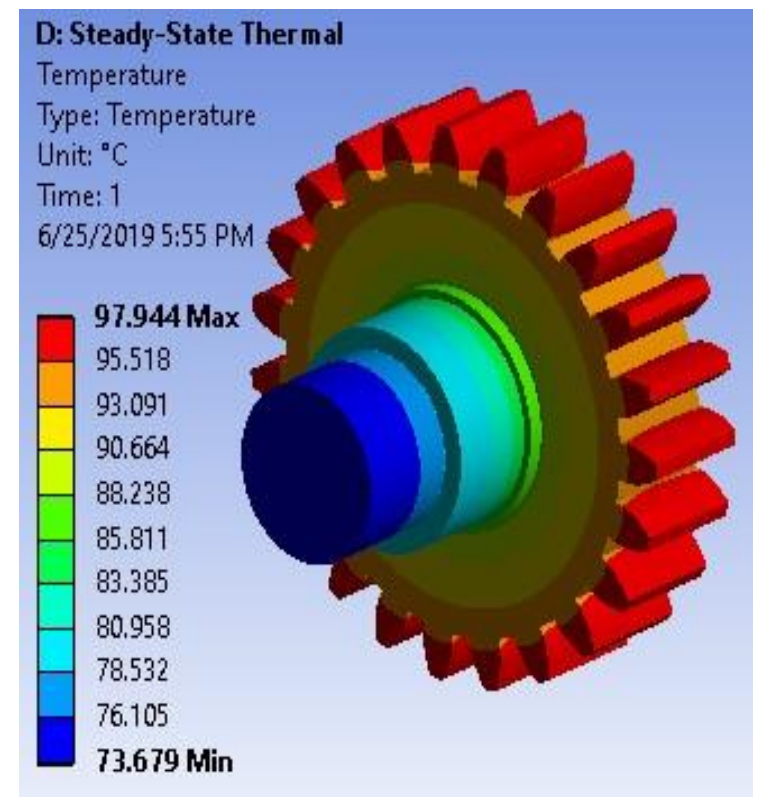

Figure Number 4-Analysis of pinion

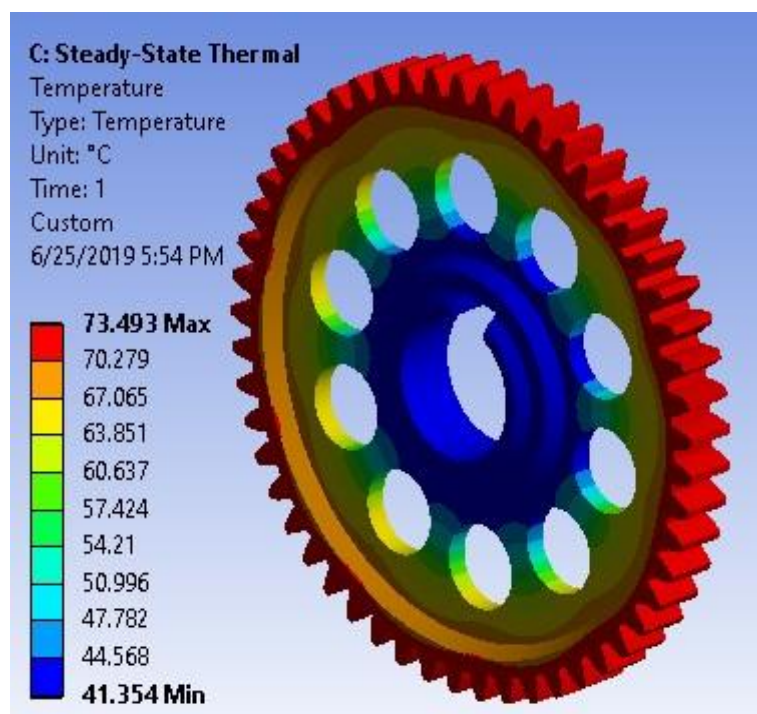

Figure Number 5- Analysis of Intermediate gear 


\section{Design of an ATV Gear Box}

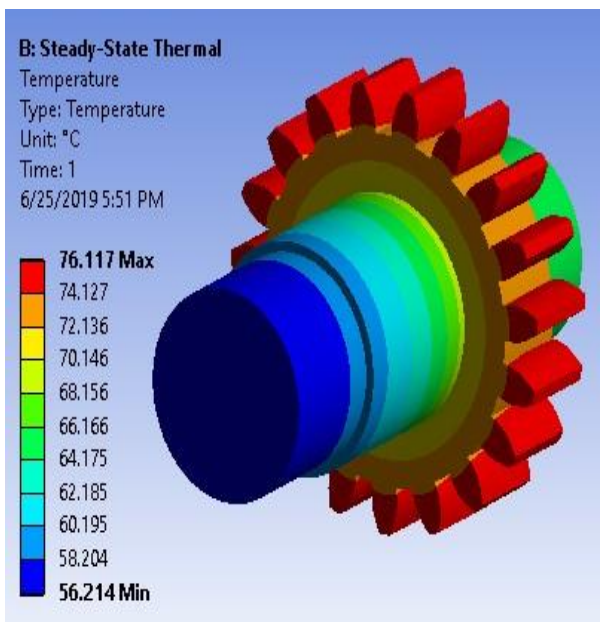

Figure Number 6- Analysis of Intermediate pinion

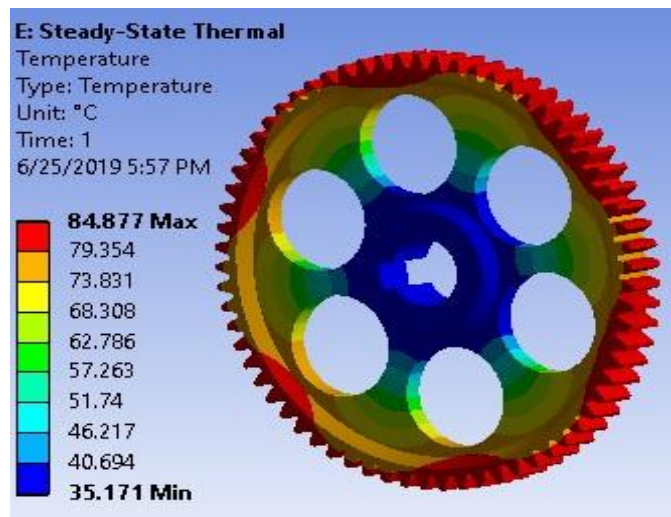

Figure Number 7- Analysis of Output gear

\section{RESULTS}

Table No. II - Tangential force

\begin{tabular}{|l|l|l|l|l|}
\hline & $\begin{array}{l}\text { Input } \\
\text { pinion }\end{array}$ & $\begin{array}{l}\text { Intermediate } \\
\text { gear }\end{array}$ & $\begin{array}{l}\text { Intermediate } \\
\text { pinion }\end{array}$ & $\begin{array}{l}\text { Output } \\
\text { gear }\end{array}$ \\
\hline $\begin{array}{l}\text { Tangential } \\
\text { force }\end{array}$ & $618.96 \mathrm{~N}$ & $618.96 \mathrm{~N}$ & $1381.26 \mathrm{~N}$ & $1381.26 \mathrm{~N}$ \\
\hline $\begin{array}{l}\text { Radial } \\
\text { force }\end{array}$ & $225.28 \mathrm{~N}$ & $225.28 \mathrm{~N}$ & $502.74 \mathrm{~N}$ & $502.74 \mathrm{~N}$ \\
\hline $\begin{array}{l}\text { Normal } \\
\text { force }\end{array}$ & $658.68 \mathrm{~N}$ & $658.68 \mathrm{~N}$ & $1469.9 \mathrm{~N}$ & $1469.9 \mathrm{~N}$ \\
\hline $\begin{array}{l}\text { Bending } \\
\text { stress }\end{array}$ & 13055.24 & 30083.82 & 24067.06 & $\begin{array}{l}92468.18 \\
\mathrm{~N} / \mathrm{mm}^{2}\end{array}$ \\
\hline $\begin{array}{l}\text { Contact } \\
\text { stress }\end{array}$ & 594.15 & $\mathrm{~N} / \mathrm{mm}^{2}$ & $\mathrm{~N} / \mathrm{mm}^{2}$ & 781.40 \\
$\mathrm{~N} / \mathrm{mm}^{2}$ & $\mathrm{~N} / \mathrm{mm}^{2}$ & $\mathrm{~N} / \mathrm{mm}^{2}$ & $\begin{array}{l}398.56 \\
\mathrm{~N} / \mathrm{mm}^{2}\end{array}$ \\
\hline Wear stress & 2326.67 & 5057.986 & 2298.03 & 9043.26 \\
& & $\mathrm{~N} / \mathrm{mm}^{2}$ & $\mathrm{~N} / \mathrm{mm}^{2}$ & $\mathrm{~N} / \mathrm{mm}^{2}$ \\
& $\mathrm{~N} / \mathrm{mm}^{2}$ & & & \\
\hline
\end{tabular}

1. A final reduction gear box was designed with the total reduction of 8.85 to propel the vehicle in forward direction only.

2. The gears designed can with stand all the forces acting on them without any failure.

3. The gear box can be used in any vehicle of $160 \mathrm{kgs}$ with Briggs and Stratton 300 cc engine and Polaris P-90 CVT.

4. The maximum torque on wheels is estimated to be 630.2 NM for overcoming obstacles in way.

\section{CONCLUSION}

A final reduction gear box was designed with total reduction 8.85 to propel the vehicle. The gear box is capable to move the vehicle to the speed of $60 \mathrm{kmph}$ and attain 0 to 60 in under 5 sec.

\section{REFERENCES}

1. Ajinkya Gulanikar and deeptikunte "design analysis and manufacturing of epicyclic gear box", international journal of mechanical engineering and research and development.

2. Dimitar Petrov, Petko Dobrev and Stanislay Alexiev "Experimental comparission of wear resistence and cyclic loading to bending between cycloidal and involute gears".

3. Xiaohe Deng Lin Hua and Xinghui Han-Research on the Design and Modification of Asymmetric Spur Gear, Volume 2015,Article ID 897257

4. V.B Bhandari, Design of Machine Elemnts, mcgraw-Hill Education, 2012.

5. Gitin Maitra, Handbook of Gear Design, McGraw-Hill, Eduction, 2012.

6. Fundamental of vehicle dynamics, Thomas D.Gillespie,1992,ISBN 1560911999,9781560911999

7. Stphen P. Radzevich, Dudley's Handbook of Practical Gear Design and Manufacture CNC press

8. D.D Chawathe Handbook of Gear Technology, New Internatyiona Publishers.

9. VD Kodigre, Material Science and Metalurgy for Engineers, Evers Publishing House.

10. PSG Design Data-Book, PSG College, Kalaikathir Achchaagam.

11. https://www.engineersedge.com/gears/gear-tooth-strength.htm

12. https://www.engineersedge.com/gears/lewis-factor.htm

13. http://www.gizmology.net/gears.htm

14. https://scholarworks.iupui.edu/bitstream/handle/1805/13632/JakeSchw artz_Thesis.pdf?sequence $=1$

15. https://www.cadit.com.sg/Solutions/Products/ANSYS_Structural_Mec hanics

\section{AUTHORS PROFILE}

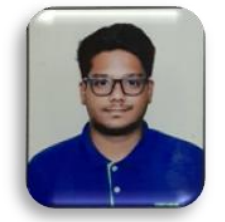

Mohit Pillai, B. Tech. Student, Mechanical Engineering Department, Medi-Caps Univesity, Indore. .Member of BAJA 2019 and 2020.

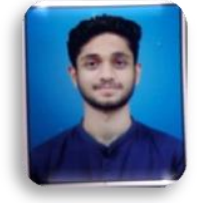

Naman Shrama, B. Tech. Student, Mechanical Engineering Department, Medi-Caps Univesity, Indore. Member of BAJA 2019 and 2020.

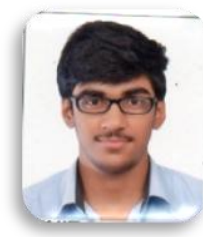

Vinit Bhandari, B. Tech. Student, Mechanical Engineering Department, Medi-Caps Univesity, Indore. Member of BAJA 2019 and 2020.

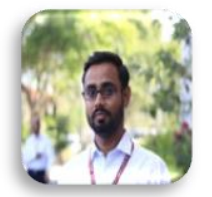

Ram Bansal, M. Tech. in automobile Engineering, Assistant Professor, Mechanical Engineering Department, Medi-Caps Univesity, Indore.

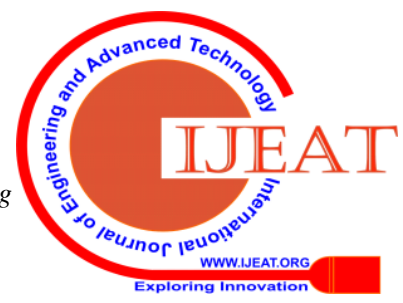

